- несовершенство организационного и правового механизма устанавливающих образование, а также осуществление деятельности ТНК на отечественном рынке и иные проблемы.

Но одновременно с этим РФ заинтересована в привлечении инвестиций на отечественный рынок поэтому соответственно совершенствует регулирование инвестиционной деятельности.

На основании вышеизложенного можно сделать вывод, что определение правового режима ТНК является не разрешенным. Отсутствует регламентация деятельности и поведения ТНК при оказании влияния на экономики, конкуренцию, рынки. При определении правосубъектности ТНК необходимо понимать, что правосубъектность присуща самостоятельным участникам корпорации.

$$
* * *
$$

1. Об утверждении Основ государственной пограничной политики Российской Федерации: указ Президента РФ от 25.04.2018 г. № 174 // СЗ РФ. - 2018. - № 18. - ст. 2614.

2. Абраменкова А.А., Липницкий Т.В. Роль транснациональных корпораций в развитии мирового сельского хозяйства // Наука, бизнес, власть - триада регионального развития: сборник статей IV международной научно-практической конференции 2019. С. 13-17.

3. Асанова Л.Р. ТНК как субъект международного частного права // Аллея науки. 2019. № 1. С. $703-705$.

4. Богуславский М.М. Международное частное право. - М.: Юрист, 2002. 462c.

5. Карпович О.Г. Регулирование международной деятельности современных транснациональных корпораций // Право и политика. - 2017. № 1. С. 47 - 58.

6. Nukusheva A., Ilyassova G., Kudryavtseva L., Popova L., Shayakhmetova Z., Jantassova A. Transnational corporations in private international law: Do kazakhstan and russia have the potential to take the lead? // Entrepreneurship and Sustainability Issues. 2020. T. 8. № 1. C. 496-512.

7. Кудрявцева Л.В., Пулин Д.В. Правовое положение транснациональных корпораций в международном частном праве // Глобальный конституционализм и перспективы мирового развития. Москва. 2021. С. 79-84.

8. Кудрявцева Л.В., Саркисян Д.С. Корпорации в международном частном праве // Аграрное и земельное право. 2020. № 10 (190). С. 72-75.

\title{
Ялмаев Р.А. \\ Роль взаимодействия как разновидности взаимоотношений государственной власти и местного самоуправления
}

Чеченский государственный университет им. А.А. Кадырова

(Россия, Грозньй)

doi: 10.18411/trnio-12-2021-202

\section{Аннотация}

В статье проведено исследование современной модели взаимодействия органов государственной власти и местного самоуправления в России. По итогам исследования автор приходит к выводу, что среди взаимоотношений муниципальных и государственных властей преобладают отношения, построенные на принципе субординации. На основе разных степеней равноправных взаимоотношений различных субъектов, автор подразделяет данные отношения на три основные категории.

Ключевые слова: взаимодействие органов государственной власти и органов местного самоуправления, субординация.

\section{Abstract}

The article studies the modern model of interaction between public authorities and local selfgovernment in Russia. According to the results of the study, the author comes to the conclusion that relations based on the principle of subordination prevail among the relations between municipal and state authorities. On the basis of different degrees of equal relations between different subjects, the author divides these relations into three main categories.

Keywords: interaction of state authorities and local self-government bodies, subordination. 
В практике деятельности местных органов самоуправления в нашей стране можно заметить достаточно высокий в последнее время уровень взаимных отношений муниципалитетов с государственными властями, предопределенный фактической нуждаемостью в продуктивной деятельности вышеназванных субъектов.

В то же время повышение степени влияния государства на деятельность местного самоуправления подразумевает под собой ослабление децентрализации, а также усиление формирования субординационного компонента взаимоотношений, на что влияет увеличение количества определенных полномочий государства, которые передаются в сферу деятельности муниципальных властей. Эти явления свидетельствуют о том, что дальнейшая судьба местного самоуправления в нашей стране неопределенна. Таким образом, в настоящее время как в теории, так и в практике государственного и муниципального управления все чаще возникают вопросы о нуждаемости в каких-либо новых, эффективных способах решения проблем взаимодействия органов государственной власти и органов местного самоуправления.

Согласно Закону № 131-Ф3 «к региональному уровню относятся следующие полномочия:

- определять ответственность в случае неисполнения правовых актов должностных лиц и органов муниципальной власти (в ч. 3 ст.7);

- $\quad$ определять и корректировать границы муниципалитетов (часть 2 ст. 10 и часть 1 ст. 12);

- преобразовывать муниципальные образования (часть 1 ст. 13), наделять отдельные городские поселения статусом городского округа (часть 2 ст. 11);

- передавать муниципалитетам некоторые полномочия органов государственной власти региона (часть 2 ст. 19);

- вводить ответственность за нарушение должностным лицом муниципалитета сроков и порядка ответа на обращения граждан (ч. 4 ст. 32);

- определять наименование представительного органа и главы муниципалитета, а также администрации муниципального образования (ч. 3 ст. 34$)$;

- $\quad$ определять условия контракта главы администрации (ч. 3 ст. 37);

- $\quad$ вводить нормы отчислений от сборов и налогов, подлежащих зачислению в бюджет субъекта РФ в соответствии с Бюджетным Кодексом РФ и иным законодательством РФ о сборах и налогах, в бюджеты муниципалитетов (часть 4 ст. 59, часть 2 ст. 58;);

- у устанавливать процедуры формирования районных и межрайонных фондов финансовой поддержки поселений (часть 4 ст. 60), городских округов, муниципальных районов (часть 1 ст. 61);

- вырабатывать и утверждать методику распределения дополнительных субсидии для местных территориальных образований (часть 2 статьи 62);

- $\quad$ определять суммарный объем субвенций, выделяемых из бюджета региона местным бюджетам для осуществления муниципалитетами переданных им государственных полномочий (часть 1 ст. 63)» [1].

Данное подробное перечисление полномочий региональных властей в сфере местного самоуправления демонстрирует, что власти субъектов РФ обладают правовыми возможностями, а в ряде случаев-прямыми обязанностями взаимодействия с органами местного самоуправления[3].

Важным является вопрос о передаче органами государственной власти органам самоуправления отдельных своих полномочий, что нередко рассматривается как проявление горизонтального типа взаимоотношений государственной и муниципальной властей, что, по 
существу, представляется неверным, поскольку в этом случае имеет место с ярко выраженными субординационными отношениями.

Часто органы государственной власти (федерального ли, регионального ли уровня) принимают решения о передаче некоторых своих полномочий муниципальным властям исключительно самостоятельно, не учитывая мнения органов самоуправления по этому вопросу, даже если таковое предварительно бывает выражено. Заметим, однако, что кажущееся сходным по смысловому наполнению право органов местного самоуправления принимать участие в реализации государственных полномочий, не переданных им, предусмотренное ст. 19 Закона № 131-Ф3, не относится к субординационным отношениям и должны быть отнесены к отношениям взаимодействия[2].

Несмотря на то, что органы местного самоуправления не входят в систему государственной власти, задачи, которые стоят перед ними представляют собой фундамент для достижения глобальных целей государства.

Область отношений, касающаяся установления оснований и порядка привлечения к ответственности должностных лиц и органов местного самоуправления очевидно менее, чем какая-либо другая может рассматриваться в контексте взаимодействий государственной власти и самоуправления.

Также исследователи уделяют внимание и вопросу принятия на себя государственной властью функций органов местного самоуправления. Полный список оснований регламентируется ч. 1 ст. 75 Закона № 131-ФЗ:

- отсутствие необходимых условий для образования органа местного самоуправления, а также местной администрации, причиной чего являются какие-либо чрезвычайные положения;

- ситуации, источником которых являются какие-либо результаты деятельности (ее отсутствия) местного самоуправления, характеризующиеся наличием просроченной денежной задолженности муниципальных органов в размере более $30 \%$ их годовых доходов в данном году или просроченной денежной задолженности муниципальных органов в размере более $40 \%$ размера бюджетных ассигнований в данном году;

- нецелевое использование бюджетных средств, предоставленных органам местного самоуправления в качестве субвенций при осуществлении ими полномочий, переданных органами государственной власти и т.д.

Можно сказать, что государственное вмешательство в сферу полномочий органов местного самоуправления преследует цель возобновления эффективного функционирования последних, что открывает значительные возможности взаимодействия государственной и муниципальной властей.

Проделанный выше анализ показывает, что среди взаимоотношений муниципальных и государственных властей преобладают отношения, построенные на принципе субординации, тем важнее представляется вопрос о том, в каких именно сферах наиболее выраженно проявляется самостоятельность муниципалитетов. Основываясь на вышеприведенных фактах можно выделить две таких сферы.

Во-первых, для муниципалитетов характерная абсолютная автономность в своей деятельности, которая проводится органами местного самоуправления без сторонней финансовой поддержки. Во-вторых, имеются области, в которых муниципалитет не в полной мере автономны, ограничивающиеся федеральным и региональным законодательством. В то же время при данных ограничениях в автономности возможно равноправное взаимоотношение органов местного самоуправления с органами государственной власти. Необходимо отметить, что такие взаимоотношения в данном случае не подразумевают равностатусности взаимодействующих субъектов.

Таким образом, учитывая вышесказанное, можно дать следующее определение: отношения взаимодействия называются такие отношения муниципальных и 
государственных властей, в которых указанные субъекты взаимоотношений выступают как равноправные, но разностатусные субъекты, независимо от степени обязательности таких отношений.

На основе разных степеней равноправных взаимоотношений различных субъектов, данные отношения могут быть подразделены на категории.

Для первой категории характерны такие отношения, в которых один из субъектов по каким-либо причинам принимает участие в осуществлении компетенций другого субъекта. Такой тип взаимоотношений является наиболее слабым взаимодействием (отношением участия). Некоторые варианты таких взаимоотношений описаны выше.

Вторая категория характеризуется скоординированной деятельностью разностатусных субъектов, которые организуются при равных правах данных субъектов. Этот тип обладает большей степенью интеграции в сравнении с первым.

К третьей категории можно отнести совместные действия, свидетельствующие о максимальной степени интеграции, возникающей при объединении возможностей и средств для выполнения каких-либо задач. Стоит подчеркнуть, что при увеличении степени интеграции, совместная деятельность характеризуется согласованностью, однако, согласованная деятельность не всегда является совместной.

В заключение, возвращаясь к вышеприведенному определению, отметим, что все виды взаимодействий могут осуществлять как на императивной (обязательной), так и на добровольной основе.

$$
* * *
$$

1. Федеральный закон от 06.10.2003 № 131-Ф3 «Об общих принципах организации местного самоуправления в Российской Федерации» // «Собрание законодательства РФ», 06.10.2003, № 40, ст. 3822

2. Административное право Российской Федерации : учебник / коллектив авторов; под ред. А.В. Мелехина. М.: Ю СТИЦИЯ, 2016. — 502 с.

3. Овчинников И.И. Местное самоуправление в Российской Федерации (теоретические, исторические и правовые аспекты). Монография. М.:

\section{Янушевская Ю.И. \\ Правовое положение несовершеннолетних в гражданском процессе}

Кубанский государственный аграрный университет им. И. Т. Трубилина (Россия, Краснодар)

doi: 10.18411/trnio-12-2021-203

\section{Аннотация}

Статья посвящена проблемам судебной защиты прав несовершеннолетних лиц в гражданском процессе, а также их правовому положению. Участие лиц, не достигших совершеннолетия, в гражданском судопроизводстве связано с определенными проблемами, как с практической, так и с теоретической точки зрения. Эти проблемы вызваны различными обстоятельствами, но в первую очередь недостатками и пробелами в правовой сфере. Одной из этих проблем, решение которой имеет большое теоретическое и практическое значение, в настоящее время является проблема определения гражданского процессуального статуса несовершеннолетнего. Актуальность проблемы, рассматриваемой в данной статье, определяется необходимостью преодоления вышеперечисленных проблем, акцентирования внимания на основу демократических принципов, установленных Конституцией Российской Федерации.

Ключевые слова: несовершеннолетние, гражданский процесс, правовой положение, правовой статус, защита. 